ISSN 2236-0859

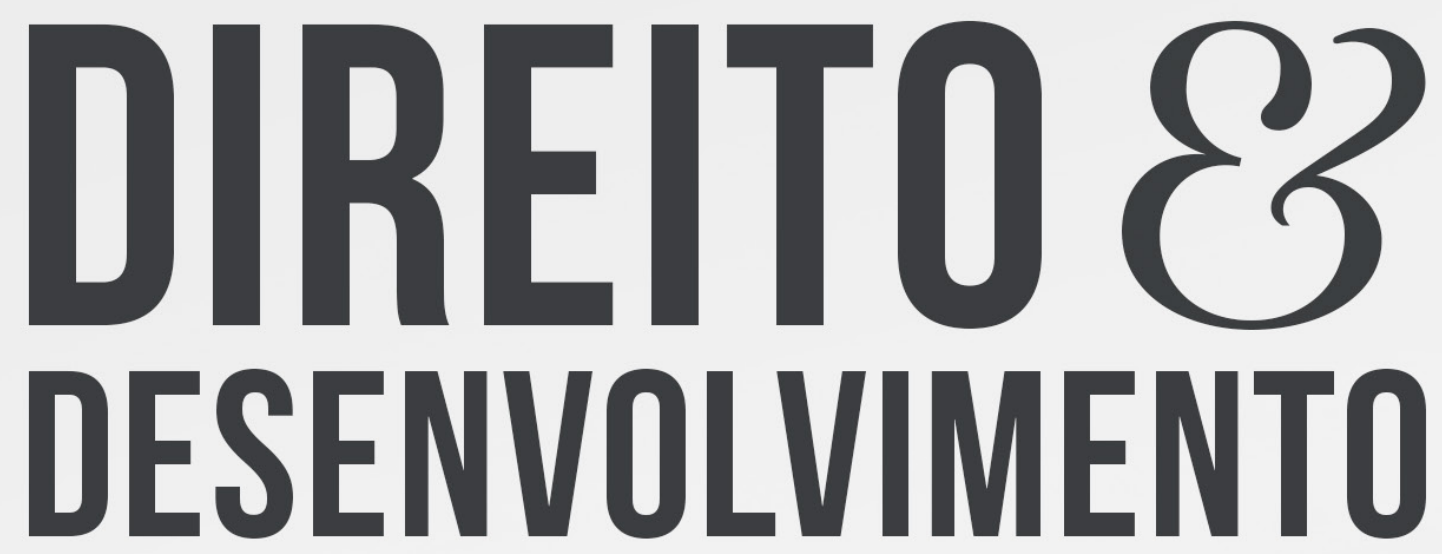

REVISTA DO PROGRAMA DE PÓS-GRADUAÇÃO EM DIREITO MESTRADO EM DIREITO E DESENVOLVIMENTO SUSTENTÁVEL

UMA REFLEXÃO CRÍTICA DO CONSTITUCIONALISMO NUMA DIMENSÃO DO MODELODE ESTADO DEMOCRÁTICO DE DIREITO: TENDÊNCIAS CONTEMPORÂNEAS

HAMILTON CUNHA IRIBURE JÚNIOR 


\title{
UMA REFLEXÃO CRÍTICA DO CONSTITUCIONALISMO NUMA DIMENSÃO DO MODELO DE ESTADO DEMOCRÁTICO DE DIREITO: TENDÊNCIAS CONTEMPORÂNEAS
}

\section{A CRITICAL REFLECTION OF CONSTITUTIONALISM IN A DIMENSION OF THE MODEL DEMOCRATIC STATE OF LAW: CONTEMPORARY TRENDS}

Recebido: $15 / 12 / 2017$

Aprovado: 30/05/2019

Hamilton Cunha Iribure Júnior ${ }^{1}$

\section{RESUMO}

O vertente artigo se assenta numa análise crítica do constitucionalismo contemporâneo à luz dos diversos modelos presentes em outros países, tendo como escopo principal avaliar sua influência e interferência na consolidação do processo democrático. Para tanto, parte-se da metodologia analítica documental, onde diversos extratos e títulos bibliográficos são investigados, com a formação, ao final, de uma síntese conclusiva. Justifica-se o presente arrazoado na carência de abordagens sobre o objeto dessa pesquisa, o constitucionalismo, à luz de um confronto com outros modelos existentes e que venham a colaborar com a formação de uma sólida base para a consolidação do Estado Democrático de Direito. É certo que numa democracia de participação popular, esta representa o ponto de convergência de toda e qualquer atividade estatal e, por tal, se faz a necessidade de delimitar-se seus contornos. Com a problemática posta e após o desenvolvimento da pesquisa, adianta-se, numa conclusão principal, que o modelo pautado na democracia participativa perfaz melhores condições para que uma quantidade significativa de instrumentos sociais sejam disponibilizados para a efetividade dos direitos e das garantias fundamentais numa ordem constitucional.

Palavras-chave: Constitucionalismo. Estado. Críticas. Contemporâneo. Modelos.

\begin{abstract}
This article is based on a critical analysis of contemporary constitutionalism in the light of the different models present in other countries, whose main purpose is to evaluate its influence and interference in the consolidation of the democratic process. It is based on the documentary analytical methodology where several extracts and bibliographical titles are investigated with the formation of a conclusive synthesis. The present reason is justified in the lack of approaches on the object of this research - the constitutionalism - in the light of a confrontation with other existing models and that will collaborate with the formation of a solid base for the consolidation of the Democratic State of Right. It is true that in a democracy of popular participation, this represents the point of convergence of state activity and for this reason, it is necessary to delimit its contours. With the problematic put and after the development of the research it is made a
\end{abstract}

1 Doutor em Direito pela Pontifícia Universidade Católica de São Paulo - PUC/SP (2009), Mestre em Direito pela Pontifícia Universidade Católica de São Paulo - PUC/SP, Professor Adjunto da Graduação e do Programa de Mestrado da Faculdade de Direito do Sul de Minas (FDSM). E-mail: hamilton.adv@terra.com.br 
main conclusion that the model based on participatory democracy makes better conditions for a significant number of social instruments to be made available for the effectiveness of rights and fundamental guarantees in an order constitutional.

Keywords: Constitutionalism. State. Critical. Contemporary. Models.

\section{INTRODUÇÃO}

A atividade estatal se associa a uma grande quantidade de fatores que, por si só, não nos permite analisar de uma única vez e de forma conclusiva os fenômenos que a ela se associam. Tarefa escarpada albergada na presente pesquisa, parte-se da premissa de que o movimento constitucional mantém uma relação estreita de dependência da forma pela qual se tem, no Estado, a maior ou menor liberdade democrática. Essa inafastável hipótese de arranque nos remete a obrigatoriamente avaliar, em linhas paralelas, como tal se permeia em vários modelos de constitucionalismo (ou vertentes do constitucionalismo) tangentes em tempos hodiernos.

Com a premissa nuclear posta, então, assenta-se a problemática central que é a viabilidade de existirem um número maior ou menor de instrumentos de exercício da cidadania vinculados ao modelo de democracia, ou, por outro lado, somente basta haver uma previsão constitucional de um fundamento ou objetivo estatal assentado na participação popular (ou na cidadania) que tais instrumentos exsurgem na ordem interna do direito infraconstitucional.

Justifica-se tal pesquisa na pauta da carência de estudos de área, que demonstram com segurança essa (im)provável relação entre o modelo democrático adotado pelo Estado e a liberdade (maior ou menor) do exercício das práticas associadas à consecução dos valores associados à cidadania. Para tanto, o desenvolvimento da presente pesquisa emprega a metodologia analítico-documental, através da técnica de pesquisa acerca dos modelos diversos existentes de constitucionalismo para que conclusões sejam, ao final, extraídas acerca dessa relação, afirmando-a no todo ou em partes, desde que possível sugerir reflexões críticas a respeito.

O exercício das atividades individuais se faz a partir de um sistema de reedificação do direito, este que, por meio do discurso, contempla o exercício simultâneo da autonomia privada e pública dos cidadãos não somente pelos discursos de justificação, mas também pelos de aplicação do Direito. A participação da sociedade passa a ser a responsável pela produção eficaz e discursiva, na medida que venha gerar decisões de cunho mais satisfatório.

Essa razão implica na necessidade de alargar os foros tradicionais da política, de maneira que os debates se estenderiam para alcançar as demais esferas sociais. O Estado de Direito deve garantir a institucionalização de mecanismos comunicativos que garantam que a arena pública - rede de comunicações intersubjetivas - possa influenciar as decisões estatais (HABERMAS, 200o, p. 111).

Nesse quadrante, tem-se que a democracia participativa se apresenta como um importante canal destinado a unir elementos do modelo liberal e republicano sob a ideia de que o processo deliberativo deve levar em consideração que o procedimento democrático não pode se restringir à mera escolha de governantes por parte da sociedade. Isso porque a troca de argumentos legitima e racionaliza as decisões, de maneira que os referidos pressupostos de deliberação seriam institucionalizados pelo Estado de Direito, porquanto o Direito passa a representar a garantia de que todas as pessoas tenham iguais possibilidades de influenciar a formação da vontade da maioria. 
A primeira grande reflexão crítica, deveras, toma assento na razão de que se vê uma tendência para um novo movimento constitucional que ganha terreno em alguns países latino-americanos (constitucionalismo andino), apresentando-se como uma emancipatória proposta e que enseja diversos mecanismos que estreitam o diálogo (sempre muito tenso) entre sociedade e Estado. Isso significa, ao sentir dessa abordagem, como verdadeiros e efetivos arranjos institucionais/sociais que permitem o exercício da democracia.

De modo muito rasteiro e à guisa de breve contextualização introdutória, cita-se o Estado Plurinacional Comunitário Colombiano que, além de reconhecer que os 36 povos originários têm direito à participação efetiva em todos os níveis estatais (art. $1^{\circ}$. e $2^{\circ}$., ambos da Constituição da Colômbia), assegura um percentual de parlamentares oriundos dos povos indígenas (art. 149, IV, da Constituição da Colômbia). Nota-se, aqui uma perfeita sintonia entre participação popular e consolidação democrática.

Em linhas similares, a Carta Constitucional do Equador prevê a formação em todos os níveis de governo de instâncias integradas por representantes do governo, do regime dependente e da sociedade (art. 100), haja vista que a participação de tais classes teria por fim o desenvolvimento de planos e políticas nacionais, locais e setoriais, o fortalecimento da democracia com mecanismos de comunicação, seja por meio de audiências públicas, seja por meio de conselhos consultivos, dentre outros. Esses e vários outros mecanismos deliberativos podem ser identificados nesse novo constitucionalismo, a exemplo da possibilidade de estrangeiros serem eleitos, algo que muito toca as razões da soberania de uma nação.

Outra premissa de igual quilate assenta-se na possibilidade de haver um efetivo exercício da democracia para além do voto, de modo a permitir uma maior participação social nas políticas públicas. Essa maior interação dos indivíduos nas decisões e tomadas de rumo que envolvem a res publica, implicam num necessário aprimoramento dos modelos constitucionais que devem passar, a partir de então, a preconizar, de modo explícito e no bojo de suas Cartas Constitucionais, instrumentos de maior abrangência e poder de emprego por parte da coletividade.

O desafio aqui é identificar, em tais modelos, os novos arranjos institucionais como forma de aperfeiçoamento das instituições democráticas. Com isso, no modelo constitucional dos países da América Latina, vê-se o reconhecimento de vários grupos e comunidades que passam a ser representados não somente no âmbito dos canais tradicionais, mas sobretudo no âmbito dos poderes Legislativo e Judiciário, por meio de uma perspectiva plural de reconhecimento e inclusão nos procedimentos de formação da vontade política.

No caso do sistema constitucional brasileiro, tem-se que a Constituição da República vigente desde 1988 preconiza que a República Federativa do Brasil deverá buscar a integração econômica, política, social e cultural com os povos da América Latina, visando formar uma comunidade latino-americana de nações (art. $4^{\circ}$., parágrafo único). Há que se concordar que tal previsão não se materializa sem que haja uma efetiva colaboração das demais nações.

Contudo, o que não se pode perder de mente é que, seja de uma forma ou de outra, exigese que práticas efetivas governamentais possam ser levadas a cabo visando ao fortalecimento interno e externo das instituições estatais, fomentando cada vez mais uma maior participação e agregação de valores da sociedade, para que os fundamentos e objetivos constitucionais não se tornem letras mortas ou poesias dentro da Carta Maior. Essas relações precisam ser refletidas para que algo de bom seja extraído à luz da consolidação democrática no Estado. 


\section{OS PARADIGMAS NO ENTORNO DO ETERNO PROBLEMA DO CONSTITUCIONALISMO POR ELE MESMO}

Analisar o constitucionalismo requer certa cautela para não confundi-lo com a simples origem da prática de escrever o Direito Constitucional, ou seja, com o advento do hábito de escrever as linhas fundamentais do Estado numa Carta Régia. A isso não deve sobrar dúvidas.

A acepção que se deve ter de um texto constitucional, da forma como hodiernamente se tem, é atribuída ao movimento das Luzes, o Iluminismo e às Revoluções Burguesas dos séculos XVII e XVIII, estando intimamente associada ao constitucionalismo moderno, movimento que aduz a necessidade de limitação do poder estatal para fins da aplicação de instrumentos garantidores à sociedade e à própria razão de ser do Estado (CANOTILHO, 1997, p. 51).

A preocupação com a limitação do poder das autoridades teve ênfase, por exemplo, na sociedade da Grécia Antiga. Visava também esta preocupação com a garantia de liberdades individuais, ou seja, o direito de tomar parte nas deliberações públicas da cidade-Estado e não da proteção de direitos do modo que se dá o constitucionalismo moderno, uma vez que, já naquela época, se tinha a ideia de que as pessoas deveriam servir à comunidade política (LOEWENSTEIN, 1976, p. 155).

A democracia - na qual os cidadãos deliberavam em assembleia reunidos em praça pública - excluía de seu bojo as mulheres, os menores de dezoito anos, os escravos e os estrangeiros, bem como seus descendentes (BONAVIDES, 2015, p. 288-289). Diz-se que a democracia grega era exclusiva em dois sentidos: i) internamente, por meio da restrição à participação nas deliberações; ii) externamente, pelo fato de que a democracia não existia entre os gregos, mas apenas entre os membros da mesma polis (DAHL, 2012, p. 32-33).

Já no direito romano, conquanto algumas instituições do período republicano tivessem alguma noção de separação dos poderes - notadamente pelas instituições como Consulado, Senado e Assembleia, representativos de estamentos sociais distintos - não se cogitava a ideia de constitucionalismo como movimento de limitação do poder do Estado em face dos direitos fundamentais. A tarefa dos republicanos romanos seria a de criar uma Constituição que refletisse o equilíbrio entre os interesses da sociedade ao proporcionar um governo misto de democracia, aristocracia e monarquia constituído de maneira que todos pudessem cooperar para o bem da coletividade (DAHL, 2012, p. 37).

Em outra toada, caminhando pela Idade Média, nota-se a existência de um pluralismo jurídico-político - ausência de um ente que detém o monopólio jurídico, o poder era fragmentado por diversas instituições e, tal peculiaridade, ao limitar cada um dos seus titulares, era tida por alguns como um componente do constitucionalismo medieval (SARLET, 2012, p. 87). Destarte, cada feudo tinha suas próprias regras jurídicas e o pluralismo impedia a expansão comercial, permitindo a convivência de diversos ordenamentos jurídicos particulares (WOLKMER, 1997, p. 21).

O Estado Moderno nasceu da aliança entre rei, burguesia e nobreza, isto é, da afirmação do rei sobre os feudos e aproximação com a burguesia que, necessitando do amparo do rei, contribuem para a construção do Estado Moderno (MAGALHÃES, 2012, p. 35). Com o passar do tempo, surge a necessidade da limitação do poder estatal frente ao indivíduo, de maneira que haja vinculação do Estado frente aos direitos fundamentais - que passam a ser exigíveis e oponíveis.

Ademais, a partir da configuração do Estado Moderno, tem-se a estatalização do direito (GROSSI, 2004, p. 45), com a monopolização da produção jurídica pelo Estado. Com a superveniente queda do absolutismo, que exerceu importante papel no tocante às bases do Estado Moderno e no desenvolvimento capitalista, tem-se o constitucionalismo moderno - 
as versões mais influentes e conhecidas são a inglesa, norte-americano e francesa - que se assentam nos pilares da contenção do poder do Estado, na separação dos poderes, na garantia de direitos fundamentais (na concepção inicial de direitos de defesa - de abstenção) e na legitimação do governo pelo consentimento do povo, pela via da democracia representativa.

Como se estava diante do liberalismo econômico, surge a necessidade de segurança nas relações desse trato, por meio de uma ordem jurídica estável, que assegurasse o direito à liberdade e, principalmente, à propriedade. O Estado, no paradigma liberal, garantia segurança às pessoas, a maior liberdade a elas, de modo que a autonomia privada está ligada aos direitos de cunho negativo.

O que se viu nesse período foi uma restrição à participação da sociedade no tocante ao sistema democrático, uma vez que se teve a adoção do voto censitário e masculino até meados do século XX sob o argumento de que apenas os homens mais instruídos teriam condições de expressar, por meio do voto, o futuro da Nação (BOBBIO, 1992, p. 129). Percebe-se, assim, que o constitucionalismo nasceu liberal e não democrático e constitucionalismo e democracia são incompatíveis com a ideia da época (MAGALHÃES, 2012, p. 36).

Em razão da grande desigualdade ocasionada pelo referido pensamento e pela consciência de classe (operária) que foi criada, percebeu-se o surgimento de movimentos sociais que proclamavam por melhores condições de vida. Passou-se, outrossim, ao Estado Social de Direito, com maior atuação do Executivo, tendo em vista que materializou a igualdade formal em material. Nesse giro, garantiu-se a progressiva extensão do direito de voto àqueles até então excluídos, mormente ao permitir que as demandas voltadas às suas reivindicações penetrassem no aparelho estatal. A democratização política fez romper a absoluta hegemonia burguesa ao abrir espaço para a democratização social.

Nota-se, contudo, que foi com o advento do paradigma do Estado Democrático de Direito, que o seu conteúdo ultrapassou o aspecto material de uma vida digna e passa agir como comentador da participação pública, apropriando do caráter incerto da democracia para veicular uma perspectiva de futuro voltada à produção de uma nova sociedade em que a questão democrática contém e implica na solução de condições materiais de existência (STRECK \& BOLZAN, 2014, p. 99).

Todavia, se o Constitucionalismo impõe a limitação do poder em face do indivíduo e a democracia pressupõe mudanças e rupturas, qual a relação entre os dois termos? Esta pressupõe mudança e reivindicações, enquanto aquele se liga à limitação do poder e supremacia da Constituição.

O Constitucionalismo não se apresenta como uma ameaça à liberdade positiva e nem a mudanças, pois ele é essencial para que se crie uma comunidade democrática - para constituir 'o povo', de maneira que não pode haver essa comunidade sem isso (DWORKIN, 1995, p. 13). Nesse prisma, as pessoas não poderão gozar de certas liberdades se elas mesmas não esclarecerem quais as justificativas e critérios pelos quais o igual deverá ser tratado como igual e o desigual como desigual (CATTONI, 2013, p. 1-2).

Essa suposta tensão entre Constitucionalismo e Democracia implica garantir "de um lado a legalidade do procedimento no sentido de uma observância média das normas que em caso de necessidade pode ser até mesmo impingida através de sanções, e, de outro, a legitimidade das regras em si, da qual se espera que possibilite a todo momento um cumprimento das normas por respeito à lei" (HABERMAS, 2007, p. 287).

Tem-se por certo que o Direito na modernidade se legitima a partir da autonomia dada a cada cidadão, de maneira que a autonomia pública e privada se inter-relacionam mutuamente. Essa concepção habermasiana implica no reconhecimento de que a relação interna entre Estado de Direito e de democracia é resultado do próprio conceito de Direito e do fato de que o 
Direito positivo não pode se legitimar por meio de um direito natural superior (HABERMAS, 2003, p. 61).

Desse embate, tem-se a ideia de mudanças com limites, mutação social com segurança - que têm por base os direitos fundamentais. Com efeito, os direitos fundamentais construídos historicamente são protegidos pela Carta Constitucional contra as maiorias provisórias que, em determinados momentos históricos, podem ceder a tentações autoritárias, fragilizando, com isso, a democracia e o próprio destino da res publica. Essa atenuação, invariavelmente, conduz a uma redução da participação popular na condução dos interesses estatais.

\section{UM NOVO CENÁRIO QUE RETRATA O MAIOR CONTEÚDO DEMOCRÁTICO DE UM ESTADO: DESAFIOS AO CONSTITUCIONALISMO}

É certo que a noção que se tem de democracia perpassa por uma perene releitura, tendo em vista ser uma constante invenção. Invenção porque implica na criação ininterrupta de novos direitos - e não apenas uma mera conservação destes (CHAUÍ, 1983, p. 7). Apesar disso, é possível visualizar algumas características que a tornam peculiar em relação às demais formas políticas.

Diversas foram as transformações sofridas para essa noção (DAHL, 2012, p. 2). A primeira foi seu exercício restrito ocorrido nas cidades-Estado. A segunda transpassou da cidade-Estado para o Estado Nacional, o que exigiu a formação de um conjunto novo de instituições políticas e é a esse novo complexo de instituições, considerado como um todo, que geralmente nos referimos como 'democracia'. Nesse diapasão, diz-se que a democracia é o único regime político e social que considera o conflito legítimo, uma vez que procura instituí-los como direitos, além de reconhecê-los e respeitá-los (CHAUÍ, 1995, p. 433).

Por outro lado não se pode se esquecer que o sistema democrático tem passado por uma crise de representatividade (BAHIA e NUNES, 2009, p. 62). Vários são os fatores que podem ser elencados como impactantes no tocante à possível crise por que passa o sistema democrático. Diz-se que, pela globalização, há uma grande influência de agentes externos nos assuntos internos, já que a política e o governo passam a sofrer influxos daquilo que se denomina por "perplexidade espaço-temporal", pois apesar de eles serem vocacionados à resolução de problemas localizados em seu território, estão, cada vez mais, sujeitos a espaços decisórios exteriores às suas fronteiras. Há, portanto, o questionamento da primazia do Estado como único regulador da política, uma vez que:

a concorrência com agências e forças econômicas transnacionais e o impacto produzido por diretrizes de ação formadas em razão do conglomerado de interesses econômicos do setor privado internacional e dos Estados hegemônicos são, pois, as causas diretas do descompasso entre os conceitos de soberania estatal e governabilidade (PEREIRA, 2008, p. 122).

Ademais, a privatização da vida tem feito com que a maior parte das pessoas auferissem maior primazia à vida privada em detrimento da pública. $\mathrm{O}$ homem da democracia direta dos tempos gregos era um ser integralmente político; hodiernamente, a política passou a ser algo acessório na vida da maior parte das pessoas. Isso porque, antes de mais nada, ele é um ser econômico (BONAVIDES, 2015, p. 293-294). Quando há referência ao homem político e econômico, está se referindo à possibilidade de que o homem tem de dar mais atenção ou mais prioridades aos assuntos de interesse particular em detrimento de temas afetos à vida políticasocial. 
Ao revés dos cidadãos atenienses, não há como se ater de todo modo à análise dos problemas do governo e da vida política se, antes disso, precisa prover suas necessidades materiais de existência (Ibidem, p. 294). Por essa razão que se sustenta a impossibilidade de participação popular em todos os atos decisórios do poder público (DALLARI, 2015, p. 152). Diante disso, vê-se a necessidade também de, cada vez mais, fortalecer as bases representativas do regime democrático.

O conceito de crise, por seu turno, deve ser associado a uma funcionalidade dinamizadora, a um momento que funda a necessidade de reflexão, abrindo-se a possibilidade de readaptação, de reforma, de rompimento (PEREIRA, 2008, p. 140). Nesse diapasão, a crise do sistema representativo tem, como um de seus principais fatores, a ausência de representação adequada dos partidos políticos, especialmente da falta de uma base ideológica definida e quando chamados a se posicionar sobre temas importantes (e polêmicos) da vida social acabam não tomando partido.

Não se pode olvidar que os partidos políticos são canais comunicativos que fazem circular o poder comunicativo e as reivindicações da periferia, isto é, são mecanismos de transmissão da opinião da grande massa social para as instâncias decisórias (SARTORI, 1982, p. 79). Assim, como instrumento de circulação da vontade dos cidadãos, os partidos devem detectar os problemas pelos quais seus representados têm passado e introduzi-los no campo das discussões políticas.

A esse papel dá-se o nome de modelo de eclusa da democracia (HABERMAS, 1997, p. 87). Desse modo, para que a sociedade possa ter influência sobre o centro (parlamento, tribunais e administração pública), os influxos comunicativos vindos da periferia - sociedade - têm de ultrapassar as eclusas dos procedimentos democráticos e do Estado Constitucional.

Durante muito tempo a representação política era fundada em uma relação de confiança e um forte vínculo entre eleitores e partidos, uma vez que grande parte daqueles se identificavam com estes e se mantinham fiel a isso (MANIN, 2016, p. 12) e, hodiernamente, as pesquisas de opinião demonstram que cresce cada vez mais o número de eleitores que não se identificam com partido algum. O que parece estar em declínio é, na verdade, as relações entre representantes e representados e a determinação das políticas públicas por parte do eleitorado (MANIN, 1996, p. 28).

Nessa esteira, além do fortalecimento dos partidos políticos, há a necessidade da complementação do sistema representativo a partir de um mecanismo deliberativo que proporcione a valorização da participação da sociedade nas instâncias decisórias como alternativa que permita a abertura de canais comunicativos. Por meio da participação discursiva no processo democrático, "os destinatários das normas são autores das mesmas" (CATTONI, 2006, p. 189).

O sistema político construído a partir do Estado Constitucional constituiria duas esferas de poder: o centro e a periferia. Para que os cidadãos - periferia - pudessem exercer influência sobre o centro - Estado (Parlamento, Tribunais e Administração) - os influxos comunicativos vindos da periferia têm que transpor as eclusas dos procedimentos democráticos e do estado constitucional.

"Na circulaçãodopoder político, odireitoéo médiumatravés doqualopoder comunicativo se transforma em poder administrativo (HABERMAS, 2003, p. 87)". A democratização do processo decisório, pois, teria dois propósitos fundamentais: "incrementar a probabilidade de acerto na tomada de decisão e compartilhar com a sociedade a responsabilidade pelas escolhas deliberadas" (PEREIRA, 2008, p. 157).

Diante disso, faz-se pertinente apresentar a possível interação entre duas perspectivas extremamente desafiadoras: a democracia deliberativa de Jürgen Habermas e a experiência 
constitucional implementada em alguns países da América Latina nos últimos anos que lançam um novo olhar que possibilite novas reflexões acerca das práticas democráticas.

Isso faz com que um novo cenário se aponte no horizonte. Não seria plausível entendelo como uma forma de ruptura com o modelo do constitucionalismo em voga hodiernamente. Seria precipitado. Por outro lado, também não se pode desprezar tal fenômeno, ou seja, há outras formas de participação popular que pintam um novo quadro com cores que desmontam o tradicional "preto e branco" com o qual se tinge o que se vem entendendo por democracia participativa.

A esse fenômeno deve-se associar a necessária reflexão com a necessidade de se criar (ou desenvolver) um modelo que permita a criação (ou ampliação dos já existentes) instrumentos garantidores dos direitos fundamentais, hábeis para torná-los cada vez mais efetivos (em sua totalidade). Desse modo se permite que sejam ventilados os ideais que cercam a democracia deliberativa, realçando seu status de valor essencial à consolidação de um Estado de Direito. Siga-se a um corte epistemológico necessário.

\section{O ENTORNO DA DEMOCRACIA DELIBERATIVA: PREMISSAS CONSTRUÍDAS A PARTIR DE UM PROCESSO CRÍTICO DA LEITURA SOCIAL}

Nem sempre o exercício das práticas cotidianas traduzem a real dimensão dos problemas. Não há soluções simplistas, por óbvio. Habermas, ao perceber que os cidadãos não teriam razões suficientes para manter as regras do jogo democrático estando limitados por uma análise autodescritiva de suas práticas empiristas, tenta retomar os modelos democráticos já introduzidos que - ao revés - possuem um conteúdo normativo. E, de acordo com sua visão, o processo deliberativo da política "constitui o âmago do processo democrático" (HABERMAS, 2003, p.18).

Para que se constitua uma democracia representativa em uma sociedade pluralista e complexa, faz-se mister que o cidadão tenha a possibilidade (real) de coparticipar do processo decisório coletivo. Sua reconstrução teórica parte do agir comunicativo dos indivíduos que fariam parte dos processos para formação do consenso (REPOLÊS, 2003, p. 67).

Para isso, as instituições hão de ser vistas além das instituições partidárias, de modo a possibilitar a abertura a uma participação discursiva da sociedade, na medida em que a autonomia individual não estaria adstrita às leis em abstrato ou aos mecanismos institucionalizados de participação, mas seria realizada por meio do discurso - formação da opinião e vontade discursiva da comunidade.

Sob o prisma liberal, o processo democrático se realizaria de maneira exclusiva mediante compromissos de interesses. E as regras de sua formação - que passa pelo direito ao voto, composição representativa, dentre outros - seriam fundamentadas em direitos de caráter liberal. Nesse diapasão, a política teria a função de englobar os interesses privados e encaminhá-los ao Estado, devendo este agir em nome daqueles. Portanto, "imagina-se o Estado como aparato da administração pública, e a sociedade como sistema de circulação de pessoas em particular e do trabalho social dessas pessoas, estruturada segundo leis do mercado" (HABERMAS, 2007, p. 277-278).

Para o referido autor, o modelo liberal não consistiria na formação democrática dos sujeitos que a delibera, mas sim na normatização constitucional e democrática da sociedade econômica. A formação democrática da vontade, outrossim, teria a função de formação da legitimidade do poder político. Assim sendo, na interpretação liberal, a formação democrática da vontade tem como função a legitimação do exercício do poder político. 
É certo que no paradigma republicano a formação da opinião e da vontade das pessoas constituiria o médium a partir do qual a sociedade se constitui estruturada politicamente, fazendo com que a democracia seja sinônimo de auto-organização política da sociedade (Ibidem, p. 20). Desse modo, tanto a sociedade civil quanto a esfera público-política seriam importantes, uma vez que o Estado seria algo construído socialmente.

A ratio do Estado não residiria fundamentalmente na proteção de direitos privados liberais, mas sim na garantia da formação abrangente da vontade e da opinião, "processo no qual os cidadãos livres e iguais chegam a um entendimento em que objetivos e normas se baseiam o interesse de todos" (HABERMAS, 1995, p. 105-106). Diante disso, o governo se torna parte de uma comunidade política que se administra.

A democracia deliberativa surgiu como uma alternativa às experiências democráticas até então predominantes, que se reduziram a um processo cujo objetivo seria a escolha de elites dominantes. Em contrariedade a isso, o processo deliberativo leva em consideração que o processo democrático não pode se restringir a mera escolha de representantes por parte da sociedade.

Além disso, ele deve envolver a possibilidade de deliberar publicamente a respeito das controvérsias a serem decididas, uma vez que a troca de argumentos e contra-argumentos, pelo menos em tese, legitimaria e racionalizaria uma decisão. E os referidos pressupostos de deliberação seriam institucionalizados pelo Estado de Direito - entendido como condição democrática, vez que não há se falar em democracia ante a ausência de respeito aos direitos fundamentais.

Para a teoria do discurso de Habermas, o desabrochar da política deliberativa não depende de uma cidadania capaz de agir coletivamente, mas da institucionalização dos respectivos processos e pressupostos comunicacionais, bem como dos que se formam de modo informal - opinião pública. A política deliberativa leva em consideração as várias formas comunicativas e sua influência na formação racional.

A formação da vontade coletiva se dará por meio da interação dos diversos atores sociais. O direito passa a representar a garantia de que todas as pessoas tenham iguais possibilidades de influenciar a formação da vontade coletiva. - que será o principal critério de delimitação da vontade da maioria. E esse processo de formação discursiva desse ocorrer de acordo com os postulados da democracia deliberativa. É como uma terceira via - alternativa às concepções liberais e republicanas - que Habermas vai apresentar a concepção de legitimação pelo procedimento democrático. O poder comunicativo - única fonte de legitimação do Estado de Direito - só se exerce nas condições ideais de uma discussão pública com a participação de todos os implicados (SIMIONI, 2007, p. 212-213).

A democracia deliberativa não está preocupada somente com a participação da sociedade na formação da vontade política, mas no modo em que ela se dá. A democracia participativa se preocupa com a inclusão, mas a deliberativa no modo em que ela se dá - que, para Habermas, deve ser legitimada pela institucionalização dos procedimentos e pressupostos comunicativos.

Uma possível interação de se fazer com a teoria de Habermas é a partir da leitura de Peter Häberle. Ele trabalha os elementos extraídos de Popper - sociedade aberta e fechada de maneira que eles traduzem, no primeiro caso, sociedades dinâmicas e plurais, onde há o surgimento constante de novos valores e, no segundo caso, fechadas a novas perspectivas (não plural). Nesse sentido, tanto a Constituição quanto a interpretação constitucional deveriam ser abertas, haja vista operar na construção de novos questionamentos que lhe são apresentados (SOUZA NETO, 2002, p. 165).

Häberle propõe alternativas ao modo tradicional de interpretação ao propô-la sob o prisma da sociedade aberta, uma vez que haveria uma estreita relação entre Constituição e 
realidade constitucional (HÄBERLE, 1997, p. 12). Essa concepção o leva a formular um conceito de sociedade aberta dos intérpretes da constituição que inclui outros atores para além dos tradicionais, que denomina de potências públicas (Cortes Constitucionais; Poder Executivo, Legislativo, autor e réu; pareceristas; associações; grupos de pressão organizados; opinião pública, dentre outros). E somente a teoria democrática poderia dar sustentação a essa aspiração forte de legitimação; seria por meio da participação no processo interpretativo que os cidadãos legitimariam as decisões proferidas.

Nota-se que, para Häberle, a democracia não estaria tão somente no campo das competências de órgãos representativos estatais (SOUZA NETO, 2002, p. 171), porquanto consistir-se-ia em uma prática quotidiana. Percebe-se, assim, que a proposta de Häberle se aproxima e muito da democracia deliberativa, na medida em que a interpretação aberta pode ser considerada um direito da cidadania (HÄBERLE, 1997, p. 41).

Há menção a algumas mudanças já realizadas no âmbito alemão, como indica na possibilidade de pronunciamento de minorias e maiorias do Legislativo Alemão em casos de controle concentrado de constitucionalidade. No âmbito brasileiro, vê-se o amicus curae, cujo procedimento foi regulado pelo Código de Processo Civil (art. 138), que permite - a depender da especificidade do tema ou da repercussão social - admitir a participação de um terceiro para que se tenha a possibilidade de aprimoramento da decisão. A intervenção do amicus curae no processo de controle de constitucionalidade, por exemplo, pluraliza o debate dos principais temas de direito constitucional e propicia uma maior abertura no seu procedimento e na interpretação constitucional.

A democracia seria o núcleo de um sistema de direitos fundamentais em que os cidadãos não seriam tão somente os destinatários de suas normas, mas também os seus atores - de maneira a participar e ter voz ativa nos processos de interpretação constitucional e o Estado de Direito é "entendido como condição de possibilidade da democracia. Sem liberdade de expressão, sem liberdade de pensamento, sem garantia do pluralismo político, não há democracia (SOUZA NETO, 2006, p. 19)".

Em suma, atribui-se um papel peculiar ao processo de formação da vontade e opinião da sociedade, de maneira que haja um espaço público não restrito ao Estado, no qual as pessoas têm poder de serem atores e receptores do processo democrático. E, nos diversos diálogos institucionais democráticos, urge voltar reflexões ao que se denomina de novo constitucionalismo latino-americano.

\section{QUADRANTES DE UM NOVO PARADIGMA VOLTADO PARA EXPERIÊNCIAS EM SISTEMAS CONSTITUCIONAIS}

Os modelos sociais expressos nas Cartas Constitucionais ensinam muito e tornam-se férteis campos de investigação. É corriqueiro, por conta disso, afirmar que o constitucionalismo havido nos diversos padrões das nações latino-americanas se traduz em Cartas Constitucionais que representam emancipação, ruptura, diálogo entre sociedade e Estado, governantes e governados, a exemplo da ideia de plurinacionalidade (OLIVEIRA e OLIVEIRA, 2011, p. 112). São, pois, arranjos institucionais que estimulam o exercício da democracia participativa.

Tais padrões nascem, sobretudo, a partir das Cartas Políticas da Bolívia (2009) e do Equador (2008), sendo compostos ainda pelas Cartas da Colômbia (1991) e da Venezuela (1999) e se apresentam como uma ruptura aos modelos do constitucionalismo europeu. A ideia do Constitucionalismo Plurinacional toma por premissa a perspectiva de que os Estados Modernos 
têm a ideia da homogeneização e da uniformização, haja vista que seus modelos tendem a negar a diversidade sociocultural.

Remonta tal noção a meados de 1492, ano que teve como marcos a invasão das Américas pelos europeus e a expulsão dos muçulmanos da Europa, desenvolvendo-se até o final do século XIX - quando se deu a formação dos últimos Estados Europeus (Alemanha e Itália). Com efeito, deu-se a predominância de um processo civilizatório de Direitos Humanos de matriz europeia, uma vez que as identidades locais foram sufocadas pela uniformização da cultura europeia que fez com que o povo tivesse sua identidade perdida. Em 1942 se tem um dos importantes marcos do nascimento da Modernidade como conceito, o momento da "origem de um mito de violência sacrifical muito particular, e, ao mesmo tempo, um processo de encobrimento do não-europeu!" (DUSSEL, 1993, p. 8).

A influência hegemônica de matriz romano-germânica influenciou não somente a cultura e o modo de vida dos povos latino-americanos, como também a própria ideia de Direito Público, notadamente no campo da positivação constitucional (WOLKMER, 2010, p. 146). Tanto a cultura jurídica quanto suas instituições derivaram da tradição europeia que, no âmbito privado, foi representada pelas tradições do direito romano, germânico e canônico.

Esse processo de uniformização cultural é um dos pontos questionados pelo novo constitucionalismo latino-americano, que preconiza o respeito à diversidade cultural e seu reconhecimento em nível constitucional. Desse modo, os vários atores sociais são reconhecidos não somente em abstrato, mas sobretudo em nível concreto, por meio de participação e representação na formação da vontade política do Estado (QUADROS, 2012, p. 121).

Certo é que a Constituição não apenas limita o exercício do poder, mas também reconhece direitos conquistados ao longo dos séculos, de modo a congregar e a refletir os horizontes pluralistas. Neste modelo, tende-se a demonstrar que o poder estatal não é a única fonte de produção do Direito, haja vista que a produção e aplicação normativa é centrada no embate e na legitimidade de um complexo sistema de poderes, porquanto tentar romper com a matriz eurocêntrica europeia, com vistas a legitimar a vontade da sociedade, seja pela aproximação hegemônica, elitista e eurocêntrica, a fim de legitimar a vontade do povo pela sua inclusão/aproximação no debate político.

Há, assim, a "proposição de um constitucionalismo pluralista e emancipador. Daí a aproximação e integração entre constituição e Pluralismo democrático, projetando a perspectiva de um novo Estado de Direito" (WOLKMER, 2010, p. 145).

Uma das principais características que distinguem a modernidade jurídica é a estatalidade do direito, o Estado como único sujeito capaz de transformar em jurídica uma vaga regra social. A consciência coletiva é subjugada por uma propaganda oficial que se aproveita da cobertura do "mito das lutas ressurgimentais para a conquista da unidade política da península e a idealização dos soberanos da casa de Savóia” (GROSSI, 2006, p. 53). Essa experiência advinda da América Latina permite a compreensão da necessidade de insurgirem novas práticas emancipatórias que têm o mérito de reconhecer uma nova pluralidade de formulações jurídicas que refletem a realidade social.

Trata-se do pluralismo de formulações jurídicas provenientes diretamente da comunidade, emergindo de vários e diversos centros de produção normativa, adquirindo um caráter múltiplo, informal e mutável. A validade e eficiência desse "Direito Comunitário" que não se sujeita ao formalismo histórico das fontes tradicionais (lei escrita e jurisprudência dos tribunais), estão embasadas nos critérios de "uma nova legitimação" gerada a partir de valores, objetivos e interesses de todo comunitário, e incorporado através da mobilização, participação e da ação compartilhada (WOLKMER, 2001, p. 219). 
Costuma-se (WOLKMER, 2010, p. 152-153) mencionar a existência de três ciclos: i) o primeiro deles tem como impulso inicial o ciclo social e descentralizador determinado pelas Constituições Brasileira (1988) e Colombiana (1991); ii) em um segundo ciclo, faz-se menção à Carta Venezuelana de 1999, na medida em que foi marcada por um constitucionalismo pluralista e participativo; iii) como expressão do constitucionalismo comunitário, marcado pelo reconhecimento de sociedades interculturais e com práticas pluralistas, o terceiro ciclo passa pelo advento das Constituições do Equador (2008) e da Bolívia (2009).

Nesse diapasão, o primeiro dispositivo da Constituição da Bolívia já consagra a instituição de um Estado Plurinacional Comunitário, fundado em um pluralismo político, econômico, jurídico, cultural e linguístico e, em seu artigo $2^{\circ}$., reconhece os 36 povos originários que têm direito à participação efetiva em todos os níveis estatais - Executivo, Legislativo e Judiciário, bem como na economia.

Ademais, a referida Carta assegura um percentual de parlamentares que são oriundos dos povos indígenas (art. 149, IV) - plurinacionalismo cultural - na medida em que, além de tal reconhecimento, passam a ter direitos exclusivos de propriedade no tocante aos recursos de suas comunidades (hídricos e florestais), do mesmo modo que reconhece a equivalência entre justiça indígena e a ordinária, de maneira que aquela poderá ter seu próprio Tribunal (arts. 189, II, 199, 200, 201).

Não bastasse isso, há dicção expressa no tocante à criação de um Tribunal Constitucional Plurinacional (MAGALHÃES, 2011, p. 2), tendo seus membros eleitores em decorrência do sistema ordinário e pelo indígena. Outro ponto peculiar é a possibilidade de os povos indígenas serem eleitos por meio de normas de suas normais comunitárias.

Nesse sentido, a Constituição do Equador prevê (art, 100) a formação em todos os níveis de governo instâncias integradas por representantes do governo, do regime dependente e da sociedade, que serão regidas pelos princípios democráticas. A participação, nesse caso, terá por fim, dentre outras, o desenvolvimento de planos e políticas nacionais, locais e sectoriais entre governos e cidadãos, o fortalecimento da democracia com mecanismos de transparência, responsabilidade e controle social, bem como a promoção de processos de comunicação, sendo que "Para el ejercicio de esta participación se organizarán audiencias públicas, veedurías, asambleas, cabildos populares, consejos consultivos, observatorios y las demás instancias que promueva la ciudadanía".

Lado outro, a democracia boliviana mescla as formas de democracia participativa, representativa e comunitárias, com equivalência das condições entre homens e mulheres (art. 11). A democracia participativa (direta) dar-se-á por meio de referendo, iniciativa legislativa, revocatória de mandato, pelas assembleias e pelos conselhos, que têm caráter deliberativo. Ademais, além da eleição de representantes populares (representativa), a deliberação comunitária permite a eleição, nomeação ou designação de autoridades e representantes de regras e procedimentos das nações e povos indígenas nativos, entre outros, de acordo com a lei.

Além disso, todos os cidadãos têm direito de participar da formação, exercício e controle do poder político, e essa participação inclui, dentre outras, a eleição direta de representantes dos povos indígenas e das nações campesino, de acordo com suas próprias regras e procedimentos (art. 26). Outra novidade - a criação do Órgão Eleitoral Plurinacional - permite a incorporação de um quarto poder, "cuja competência consistiria em controlar e supervisionar os processos de representação política” (SANTOS, 2010, p. 86-88).

Em dicção similar, a Carta Colombiana prevê como mecanismos de democracia direta a utilização de plebiscito, referendo, a consulta popular, fóruns abertos, a iniciativa legislativa e remoção de funcionários (art. 103). Outro arranjo institucional interessante é o que possibilita o Presidente da República, com a anuência dos Ministros e parecer favorável do Senado, de 
consultar a população em decisões de importância nacional, desde que não concomitante a outra (art. 104). Do mesmo modo, os governadores e prefeitos conforme o caso podem realizar consultas populares para decidir sobre questões da competência do respectivo departamento ou município (art. 105).

Noutro giro, outros dispositivos das Constituições que compõe esse constitucionalismo andino aduzem que os membros das Cortes Supremas da Venezuela e da Bolívia são escolhidos por meio de um sufrágio universal - mecanismo de participação da sociedade nas decisões governamentais. Ademais, os membros do primeiro Tribunal podem ser removidos pela Assembleia Constitucional por manifestação popular prévia, ou até mesmo ter o mandado revogado pela população.

No Equador, o quórum estabelecido pelo sistema constitucional é de o,25\% para leis e o1\% atinentes às emendas, com uma peculiar característica: apesar de o chefe do Executivo poder modifica-lo, não poderá vetá-lo totalmente e, se não apreciado em até cento e oitenta dias entrará em vigência imediatamente; do mesmo modo, caso os projetos de emenda constitucional não forem apreciados em até um ano, poderá ser solicitado ao Congresso que convoque consultar popular para deliberar a respeito do tema. Outro ponto da que contribui para uma maior implementação da democracia participativa é o que prevê o referendo como mecanismo legitimador da mudança do texto constitucional (Venezuela e Bolívia).

Esses e vários outros arranjos institucionais poderiam ser aqui demonstrados (a exemplo do direito de voto a estrangeiro, o controle preventivo de constitucionalidade de projetos de lei e de tratados, dentre outros). É preciso repensar e investir em novos mecanismos de democracia direta - em diálogos sociais - de maneira a aniquilar os défices de representação e, principalmente, estabelecer maior interação entre centro e periferia.

\section{CONCLUSÕES}

O constitucionalismo, como movimento que traduz os ideais da atuação dos indivíduos nos quadrantes da vontade estatal, é campo fértil para que se realizem diversas investigações científicas. Tarefa escarpada (e muitas vezes inconclusiva) é estudá-lo, por sua dinâmica e feição, por seu arranjo e pela gama de modelos que o cercam. Contudo, a reflexão proposta neste artigo evidencia a necessidade de se voltar os olhos às novas formas de participação democrática advindas nos últimos tempos, especialmente aos contributos que se podem extrair da onda latino-americana, por refletir um modelo extremamente inclusivo e que reconhece e efetiva a diversidade cultural por meio de práticas democráticas.

A proposta deliberativa de Jürgen Habermas representa uma maior interação entre o centro e a periferia, isto é, há a abertura do canal comunicativo entre a sociedade e o Estado, de maneira que os próprios destinatários das prestações estatais passam a ser, ao mesmo tempo, atores e receptores. Além disso, em face da suposta crise de representatividade e da necessidade de fortalecimento dos partidos políticos - canais comunicativos que fazem circular o poder comunicativo e as reivindicações da periferia, vez que mecanismos de transmissão da opinião da grande massa social para as instâncias decisórias - vê-se na democracia deliberativa um importante instrumento de resgate daquilo que se denomina democracia - o governo do povo e pelo povo.

O paradigma do Estado Democrático de Direito, que tem na cidadania um agir discursivo, por meio dos espaços de discussões públicas em que se permita a participação de diferentes grupos, sem que se dependa que a decisão parta pronta do centro, permite o reconhecimento das diferenças. Não obstante a fala de Habermas, em grande parte, seja dirigida ao mundo 
ocidental e voltada para o conjunto das sociedades do capitalismo avançado, há de se aduzir que é possível a elaboração de processos abertos e dialógicos para uma democracia deliberativa.

Ademais, demonstrou-se que devido à colonização e europeização pela qual se passaram os países latino-americanos, especialmente das experiências advindas do monismo jurídico europeu, e o surgimento cada vez maior de diversas pluralidades sociais, emergiram novas possibilidades de um novo modelo constitucional, contrapondo um sistema de unidade estatal e permitindo a ressignificação do sistema democrático e de justiça.

Esse pluralismo democrático-participativo implica em uma proposta emancipatória, por meio da qual se reconhece a possibilidade de práticas comunitárias e se respeita a diversidade cultural, rompendo com o paradigma dominante do colonialismo.

Com efeito, não se tem somente o reconhecimento formal das diferenças, que a Constituição Brasileira o faz por meio de diversos dispositivos, mas, muito mais do que isso, o constitucionalismo latino-americano permite a efetivação da diversidade e do pluralismo em face dos quinhentos anos da imposição da colonização de matriz europeia. Esse constitucionalismo multicultural, plural e democrático de caráter inclusivo é o atual desafio a ser repensado pela Teoria da Constituição e da Democracia.

\section{REFERÊNCIAS}

BAHIA, Alexandre; NUNES, Dierle. Crise da Democracia Representativa - Infidelidade Partidária e seu Reconhecimento Judicial. Revista Brasileira de Estudos Políticos, Belo Horizonte, n. 100, p. 57-84, jan./jun. 2010.

BOBBIO, Norberto. O futuro da Democracia: uma defesa das regras do jogo. Trad: Marco Aurélio Nogueira. 6. ed. Rio de Janeiro: Paz e Terra, 1997.

BONAVIDES, Paulo. Ciência política. 22. ed. São Paulo: Malheiros, 2015.

CANOTILHO, José Joaquim Gomes. Direito constitucional e teoria da constituição. 4. ed. Coimbra: Almedina, 1997

CATTONI, Marcelo de Oliveira. Devido Processo Legislativo. 2. ed. Belo Horizonte: Mandamentos, 2006.

Coesão Interna entre Estado de Direito e Democracia na Teoria de Jürgen Habermas. Disponível em: <http://www.fmd.pucminas.br/Virtuajus/ano2_2/Coesao\%2ointerna.pdf>. Acesso em: 11/04/2017.

. Contribuições para uma Teoria Discursiva da Constituição e do Processo Constitucional. In: Teoria do Processo: um panorama doutrinário mundial. Org.: Fredie Didier JR. Salvador: JusPodivm, 2010.

CHAUÍ, Marilena de Souza. Cultura e Democracia: o discurso competente e outras falas. 3.ed. São Paulo: Moderna, 1983.

In: Leforte, Claude. A invenção democrática. São Paulo: Brasiliense, 1995. 
DAHL, Roberto Alan. A democracia e seus críticos. Trad.: Patrícia de Freitas Ribeiro. São Paulo: Martins Fontes, 2012.

DALLARI, Dalmo de Abreu. Elementos de teoria geral do Estado. 32. ed. São Paulo: Saraiva, 2013.

DUSSEL, Enrique. 1492: o encobrimento do outro: a origem do mito da modernidade, conferências de Frankfurt. Trad.: Jaime A. Classen. Petrópolis: Vozes, 1993.

DWORKIN, Ronald. Constitucionalismo e democracia. Trad.: Emílio Peluso Neder Meyer. European Journal of Philosophy, v. 3, n. 1, p. 2-11, 1995.

GROSSI, Paolo. Mitologias jurídicas da modernidade. Florianópolis: Fundação Boiteux, 2004.

_-____. Primeira lição sobre direito. Trad.: Ricardo Marcelo Fonseca. Rio de Janeiro: Forense, 2006.

HABERLE, Peter. Hermenêutica Constitucional. A sociedade aberta dos intérpretes da Constituição: Contribuição para a Interpretação Pluralistae 'Procedimental'da Constituição. Trad.: Gilmar Ferreira MENDES. Porto Alegre: Sergio Antonio Fabris, 1997.

HABERMAS, Jürgen. A inclusão do outro: estudo de teoria política. 3. ed. São Paulo: Edições Loyola, 2007.

Consciência moral e agir comunicativo. 2. ed. Rio de Janeiro: Tempo Brasileiro, 2003.

Direito e democracia I: entre facticidade e validade. 2. ed. Rio de Janeiro: Tempo Brasileiro, 2003.

. Direito e democracia II: entre facticidade e validade. 2. ed. Rio de Janeiro: Tempo Brasileiro, 2003.

.Remarks on erhard denninger's triad of diversity, security, and solidarity. Constellations, Oxford, n. 4, v. 7, 2000.

. Teoria do agir comunicativo. Racionalidade da ação e racionalização social. 3. ed. São Paulo: Martins Fontes, 2012.

. Teoria do agir comunicativo, 2: Sobre a crítica da razão funcionalista. 3.e d. São Paulo: Martins Fontes, 2012.

. Teoria Política: três modelos normativos de democracia. Cadernos da Escola do Legislativo: Belo Horizonte, v. 3, 1995.

HABERMAS, Jürgen. Sobre a coesão interna entre Estado de Direito e democracia. In: $A$ inclusão do outro: estudos de teoria política. Trad.: George Sperber \& Paulo Astor Soethe. São Paulo: Loyola, 2002. 
LEITÃO, Cláudia. A Crise dos Partidos Políticos Brasileiros: os dilemas de representação política no estado intervencionista. Fortaleza: Gráfica Tiprogresso, 1989.

LOEWENSTEIN, Karl. Teoria de la Constitución. Trad.: Alfredo Gallego Anabidarte. Barcelona: Ariel, 1976.

MAGALHÃES, José Luiz Quadro de. O Estado Plurinacional na América Latina. Belo Horizonte: Arraes, 2011.

BRANT, Leonardo Nemer Caldeira. Estado plurinacional e direito internacional. Curitiba: Juruá, 2012.

MANIN, Bernard. As Metamorfoses do Governo Representativo. Disponível em: < http://www. anpocs.org.br/portal/publicacoes/rbcs_oo_29/rbcs29_o1.htm>. Acesso em: 07/o6/2017.

NOVAES, Adauto. O esquecimento da política. Rio de Janeiro: Agir, 2007.

OLIVEIRA, Larissa Pinha de; OLIVEIRA, Fábio Corrêa Souza de. Abrindo, lendo e escrevendo as páginas do romance em cadeia: diálogos, backlash e hermenêutica. Juris Poiesis. Rio de Janeiro: CRV, n. 14, p. 103-132, 2011.

PEREIRA, Rodolfo Vianna. Direito Constitucional Democrático: Controle e Participação como Elementos Fundantes e Garantidores da Constitucionalidade. Rio de Janeiro: Lumen Juris, 2008.

REPOLÊS, Maria Fernanda Salcedo. Habermas e a Desobediência Civil. Belo Horizonte: Mandamentos, 2003.

SARLET, Ingo Wolfgand. Constitucionalismo: trajetória histórica e dilemas contemporâneos. In: SARLET, Ingo Wolfgang; LEITE, George Salomão (coords). Jurisdição Constitucional, Democracia e Direitos Fundamentais: Estudos em homenagem ao Ministro Gilmar Ferreira Mendes. Salvador: JusPodivm, 2012.

SARTORI, Giovani. Partidos e Sistemas Partidários. Trad.: Waltensir Dutra. Rio de Janeiro: Zahar, 1982.

SCHAFER, Walter Reese. Compreender Habermas. 2.ed. Petrópolis: Vozes, 2009.

SIMIONI, Rafael Lazzarotto. Direito e racionalidade comunicativa: a teoria discursiva do direito no pensamento de Jürgen Habermas. Curitiba: Juruá, 2007.

SOUZA FILHO, Carlos Frederico Marés de. O renascer dos povos indígenas para o direito. Curitiba: Juruá, 2012.

SOUZA NETO, Cláudio Pereira de. Jurisdição constitucional, democracia e racionalidade prática. Rio de Janeiro: Renovar, 2002.

STRECK, Lenio Luiz; MORAIS, José Luis Bolzan de. Ciência política e teoria do Estado. 7. ed. Porto Alegre: Livraria do Advogado, 2012 
WOLKMER, Antônio Carlos. Pluralismo crítico e perspectivas para um novo constitucionalismo na América Latina. In: WOLKMER, Antonio Carlos; MELO, Milena Petters (Orgs.). Constitucionalismo latino-americano: tendências contemporâneas. Curitiba: Juruá, 2013.

WOLKMER, Antônio Carlos. Pluralismo jurídico e crítica do constitucionalismo na América Latina. Academia Brasileira de Direito Constitucional, 2010. Disponível em: http://www. abdconst.com.br/revistaz/antoniowolkmer.pdf. Acesso em: 04/o6/2017.

. Pluralismo Jurídico: fundamentos de uma nova cultura no Direito. 3. ed. São Paulo: AlfaÔmega, 2001.

Síntese de uma história das ideias jurídicas: da Antiguidade clássica à Modernidade. Florianópolis: Fundação Boiteux, 2006.

FAGUNDES, Lucas Machado. Tendências contemporâneas do constitucionalismo latino-americano: Estado plurinacional e pluralismo jurídico. Disponível em: <http://ojs.unifor. br/index.php/rpen/article/view/2158.> Acesso em: 07/o6/2017. 